\title{
PENILAIAN EFISIENSI UNIVERSITAS LPTK DI INDONESIA DENGAN MENGGUNAKAN DATA ENVELOPMENT ANALYSIS
}

\author{
Handaru Jati \\ Program Studi Pendidikan Teknik Informatika Universitas Negeri Yogyakarta \\ handaru@uny.ac.id
}

\begin{abstract}
ABSTRAK
Seiring meningkatnya keinginan untuk melanjutkan kuliah ke Perguruan Tinggi bagi lulusan sekolah menengah di Indonesia dan semakin tingginya biaya yang ditanggung oleh calon mahasiswa, pemerintah dihadapkan pada kondisi untuk mendorong universitas agar dapat beroperasi dengan lebih efisien dan lebih produktif. Tujuan penelitian ini adalah mengembangkan metode baru penilaian efisiensi universitas Lembaga Pendidikan Tenaga Keguruan (LPTK) di Indonesia dengan mempergunakan Data Envelopment Analysis yang secara teknis efektif untuk menghitung efisiensi sebuah Universitas. Penelitian ini merupakan penelitian research and development yang dilaksanakan dalam kegiatan yang meliputi analisis kebutuhan yaitu pengkajian variabel yang akan menjadi factor penilaian efisiensi beserta mekanisme pengumpulan datanya, disain model perhitungan efisiensi dari Lembaga Pendidikan Teknologi dan Kejuruan serta implementasi perhitungan efisiensi dan produktivitas dari 6 Universitas LPTK negeri di Indonesia dengan Data Envelopment Analysis. Hasil dari perhitungan DEA menunjukkan bahwa Universitas di Jawa memiliki rata-rata efisiensi yang lebih baik dibanding dengan Universitas LPTK di luar Jawa.
\end{abstract}

Kata kunci : Efisiensi, produktivitas, LPTK, Data Envelopment Analysis, Malmquist Index

\section{PENDAHULUAN}

\section{LatarBelakang}

Kinerja Lembaga Pendidikan Tinggi telah menjadi subyek perhatian yang tumbuh dalam beberapa tahun terakhir. Pertanyaan tentang bagaimana sumber daya publik harus dialokasikan dalam pendidikan tinggi telah menyebabkan timbulnya kebutuhan akan adanya model dan mekanisme yang nantinya dapat mengukur efisiensi dan produktivitas dari Lembaga Pendidikan Tinggi. Tiap Negara memiliki kebijakan tersendiri dalam pengaturan pembiayaan Lembaga Pendidikan Tinggi dan struktur alokasi sumber daya. Permasalahan penentuan Uang Kuliah Tunggal untuk biaya pendidikan Perguruan Tinggi juga menjadi hal selalu dibicarakan di Kementrian Pendidikan dan Kebudayaan Nasional. Beberapa penelitian telah dilakukan untuk membahas masalah ini pada level internasional.Penelitian dilaksanakan menggunakan analisis statistik untuk mengukur kinerja, sementara yang lain menggunakan instrumen non-statistik.

Sektor pendidikan secara substansial sangat bervariasi. Oleh karena itu perlu berhatihati dalam menentukan indicator kinerja untuk analisis efisiensi dan produktivitas perguruan Tinggi. Ada dua aspek utama dalam dunia Pendidikan Tinggi : pertama lembaga pendidikan beroperasi di bawah kondisi dan lingkungan yang berbeda yaitu negeri dan swasta. Kedua, sector produksi pendidikan mengandung banyak input dan output. Menurut data di DIKTI tahun 2013 terdapat 92 PTN dan ribuan PTS di Indonesia (www.dikti.go.id).

Untuk pengukuran kinerja Lembaga Pendidikan Tinggi diperlakukan sebagai unit produktif sama dengan seperti unit bisnis, yaitu membutuhkan masukan untuk mencapai tingkat output tertentu. Beberapa contoh Indikator kinerja yang dipakai adalah proporsi mahasiswa pada tahun tertentu dan biaya per mahasiswa sebagai imput atau banyaknya mahasiswa yang diluluskan pada tahun ajaran berjalan dan waktu tunggu kerja sebagai output. Input dan output diperlukan untuk 
menentukan efisiensi dan produktifitas dalam Lembaga Pendidikan Tinggi negeri dan swasta. Selain itu, beberapa hal yang khusus melekat pada sektor pendidikan juga harus dipertimbangkan saat menghitung efisiensi. Dengan demikian tujuan dari penelitian ini adalah untuk mendapatkan model dan menghitung efisiensi dan produktivitas lembaga Pendidikan Tinggi dan kemudian menyusun peringkat dari yang paling ke paling tidak efisien yang nantinya dipergunakan untuk memberikan masukan kepada pemerintah guna menentukan alokasi sumberdaya yang optimal kepada Lembaga Pendidikan Tinggi.

Secara khusus tujuan penelitian ini mengembangkan sebuah model yang dapat dipakai untuk menghitung efisiensi dan produktivitas Perguruan Tinggi LPTK di Indonesia dengan menggunakan metode Data Envelopment Analysis yang nantinya akan dikembangkan menjadi sebuah informasi yang bermanfaat sebagai basis data input dan output dari perguruan Tinggi LPTK dan universitas di Indonesia. Secara metodologis, pengembangan metode penilaian efisiensi dan produktivitas dengan metode Data Envelopement Analysis dan Malmquist akan meningkatkan kualitas dan obyektivitas penilaian kinerja Universitas di Indonesia (Altbach, 2004).

\section{METODE PENELITIAN}

\section{DesainPenelitian}

Penelitian ini merupakan penelitian dengan rancangan research and development yang dilakukan dalam tiga tahap. Tahap pertama adalah analisis kebutuhan dari pengembangan model penilaian efisiensi dari Lembaga Pendidikan Tenaga Keguruan serta pengkajian input dan output beserta bobot yang nantinya akan mempengaruhi indikator kinerja, tahap kedua yaitu disainpenilaian efisiensi dengan menggunakan perangkat lunak yang akan dipakai serta tahap ketiga yaitu implementasi model penilaian efisiensi dalam bentuk rangking Universitas LPTK yang menjadi sampel penelitian.

Penelitian ini akan difokuskan pada analisis efisiensi Lembaga Pendidikan Tenaga Keguruan yang meliputi penilaian terhadap 6 Lembaga Pendidikan Tenaga Keguruan di Indonesia dengan mengambil teknik analisis data primer dan sekunder serta uji statistik diskriptif tentang kinerja LPTK.

\section{Sampel}

Pada penelitian ini yang dipergunakan adalah 12 LPTK berbentuk Universitas di Indonesia yang meliputi 6 Universitas LPTK di Jawa yaitu : UPI Bandung, UNJ Jakarta, UNNES Semarang, UNESA Surabaya, UNY Yogyakarta, UM Malang serta 6 Universitas LPTK di luar Jawa yaitu UNP Padang, UNM Makassar, Unimed Medan, Universitas Negeri Manado, Undhiksa Singaraja, serta UNG Gorontalo.

\section{ProsedurPengumpulan Data}

Pengumpulan data dilakukan dengan menggunakan sejumlah instrumen yang tersedia di Internet dan data primer di dari DIKTI, berikut ini adalah tabel berisi variabel, kategori batasan dari indikator tersebut, sertaalat/tool yang dipakai untuk mengukur indikator. Proses pengambilan data dari web dengan menggunakan beberapa situs resmi yang dimiliki oleh DIKTI dan Kemendiknas serta Google Scholar. Beberapa variabel output juga didapatkan melalui mesin pencarian Google untuk mendapatkan data mengenai jumlah paper yang di-publish yang ada di tiap-tiap universitas yang berkaitan dengan produktivitas civitas akademika. Pada Tabel 1 menerangkan tentang variabel, jenis variabel, batasan variabel dan cara pengumulan data dari penelitian. 
Tabel 1.VariabelPenelitiandanAlatPengukurannya

\begin{tabular}{|l|l|l|l|l|}
\hline No & \multicolumn{1}{|c|}{ Variabel } & Kategori & Batasan dari variable & \multicolumn{1}{|c|}{ Alat pengukuran } \\
\hline 1 & $\begin{array}{l}\text { Banyaknya jumlah dosen di } \\
\text { perguruan Tinggi (Coelli, 1998) }\end{array}$ & Input & $\begin{array}{l}\text { Banyaknya dosen } \\
\text { yang berstatus dosen } \\
\text { tetap }\end{array}$ & $\begin{array}{l}\text { Data Dikti } \\
\text { http://pdpt.dikti.go.id/ }\end{array}$ \\
\hline 2 & $\begin{array}{l}\text { Banyaknya jumlah mahasiswa } \\
\text { aktif(flegg, 2003) }\end{array}$ & Input & $\begin{array}{l}\text { Banyaknya } \\
\text { mahasiswa s1,s2, } \\
\text { dan s3 }\end{array}$ & $\begin{array}{l}\text { Data } \\
\text { Diktihttp://pdpt.dikti.go.id/ }\end{array}$ \\
\hline 3 & $\begin{array}{l}\text { Produktivitas dari proses } \\
\text { pembelajaran (flegg, 2003) }\end{array}$ & output & $\begin{array}{l}\text { Banyaknya materi } \\
\text { ajar dan bahan ajar } \\
\text { di internet }\end{array}$ & Scholar.google.com \\
\hline 4 & $\begin{array}{l}\text { Banyaknya Program Studi yang } \\
\text { mendapat akreditasi A }\end{array}$ & output & $\begin{array}{l}\text { Program studi yang } \\
\text { diselenggarakan di } \\
\text { Universitas yang } \\
\text { bersangkutan }\end{array}$ & ban-pt.kemdiknas.go.id \\
\hline
\end{tabular}

$$
\begin{gathered}
D_{0}^{t}\left[x^{t+1}, u^{t+1} / C R T S\right]^{-1}=\operatorname{Max} \lambda \\
\text { Subject untuk } \sum \lambda_{\mathrm{i}} \mathrm{x}_{\mathrm{i}}^{\mathrm{t}} \leq \mathrm{x}^{\mathrm{t}+1} \\
\sum \lambda_{i} u_{\mathrm{i}}^{t} \geq \lambda u^{t+1} \\
\lambda \geq 0 \\
D_{0}^{t+1}\left[x^{t}, u^{t} / C R T S\right]^{-1}=\operatorname{Max} \lambda \\
\text { subject untuk } \sum \lambda_{i} x_{i}^{t} \leq x^{t} \\
\sum \lambda_{\mathrm{i}} \mathrm{u}_{\mathrm{i}}^{\mathrm{t}} \geq \lambda \mathrm{u}^{\mathrm{t}} \\
\lambda \geq 0 \\
D_{0}^{t+1}\left[x^{t+1}, u^{t+1} / C R T S\right]^{-1}=\operatorname{Max}^{\lambda} \\
\text { Subject untuk } \sum \lambda_{\mathrm{i}} \mathrm{x}_{\mathrm{i}}^{\mathrm{t}+1} \leq \mathrm{x}^{\mathrm{t}+1} \\
\sum \lambda_{\mathrm{i}} \mathrm{u}_{\mathrm{i}}^{\mathrm{t}+1} \geq \lambda \mathrm{u}^{\mathrm{t}+1} \\
\lambda \geq 0 \\
\lambda \geq 0 \\
D_{0}^{t}\left[x^{t}, u^{t} / C R T S\right]^{-1}=\operatorname{Max}^{2} \lambda \\
\text { Subject untuk } \sum \lambda_{\mathrm{i}} \mathrm{x}_{\mathrm{i}}^{\mathrm{t}} \leq \mathrm{x}^{\mathrm{t}} \\
\sum \lambda_{\mathrm{i}} \mathrm{u}_{\mathrm{i}}^{\mathrm{t}} \geq \lambda \mathrm{u}^{\mathrm{t}} \\
\lambda \geq 0
\end{gathered}
$$


Dimana K, N, M, dan T mewakili jumlah dari Universitas, input, output dan periode waktu yang dijadikan sampel.

Pada penelitian ini $\mathrm{K}=12, \mathrm{~N}=2, \mathrm{M}=2$ and $\mathrm{T}=1$, Time Period: $\mathrm{t}=2013$ dan $\lambda$ 's adalah parameter intensitas. Keempat persamaan linear diperlukan untuk masingmasing unit produksi (Total produksi dari masing-masing universitas dari penelitian).

\section{HASIL DAN PEMBAHASAN}

DEA menggunakan rasio total faktor produktivitas untuk mengukur kinerja (yaitu rasio tunggal dengan semua input dan output). DEA memberikan bobot kepada masing masing variabel input dan output. Masing masing entitas dari DMU kemudian diukur dengan menggunakan proses optimasi linear yang mencoba mendapatkan nilai maksimal dari masing masing rasio entitas dengan mencari nilai bobot yang paling baik untuk masing masing entitas. Data tersebut didapatkan dengan menggunakan halaman informasi yang disediakan oleh dikti yaitu : http://pdpt.dikti.go.id, http:/ban-pt.kemdiknas.go.id, dan http://scholar.google.com.

Tabel 2 Adalah data yang didapatkan dari sumber resmi tentang variabel input dan output yang dibutuhkan dalam penilaian efisiensi sebuah universitas.

Tabel 2. Hasil Pengumpulan data mengenai input dan output Universitas

\begin{tabular}{|l|c|c|c|c|}
\hline \multicolumn{1}{|c|}{ Universitas } & $\begin{array}{c}\text { Jumlah Staf } \\
\text { pengajar } \\
\text { tetap (input) }\end{array}$ & $\begin{array}{c}\text { Jumlah } \\
\text { mahasiswa } \\
\text { (input) }\end{array}$ & $\begin{array}{c}\text { Jumlah } \\
\text { publikasi/biblio } \\
\text { metric (output) }\end{array}$ & $\begin{array}{c}\text { Jumlah prodi } \\
\text { terakreditasi A } \\
\text { (output) }\end{array}$ \\
\hline Universitas Negeri Padang & 992 & 31.426 & 13500 & $12 / 69=0,1739$ \\
\hline Universitas Negeri Malang & 901 & 23.653 & 43100 & $30 / 78=0,3846$ \\
\hline $\begin{array}{l}\text { Universitas Pendidikan } \\
\text { Indonesia }\end{array}$ & 1.301 & 28.948 & 122000 & $56 / 114=0,4912$ \\
\hline $\begin{array}{l}\text { Universitas Negeri } \\
\text { Manado }\end{array}$ & 943 & 14.881 & 2980 & $0 / 43=0$ \\
\hline $\begin{array}{l}\text { Universitas Negeri } \\
\text { Makassar }\end{array}$ & 874 & 23.540 & 6630 & $8 / 69=0,1159$ \\
\hline Universitas Negeri Jakarta & 944 & 21.003 & 79000 & $22 / 81=0,2716$ \\
\hline $\begin{array}{l}\text { Universitas Negeri } \\
\text { Yogyakarta }\end{array}$ & 1.024 & 22.692 & 61800 & $29 / 82=0,3537$ \\
\hline $\begin{array}{l}\text { Universitas Negeri } \\
\text { Surabaya }\end{array}$ & 837 & 23.237 & 28400 & $15 / 72=0,2083$ \\
\hline Universitas Negeri Medan & 942 & 15.661 & 29800 & $8 / 48=0,1667$ \\
\hline $\begin{array}{l}\text { Universitas Negeri } \\
\text { Semarang }\end{array}$ & 1.026 & 29.316 & 56900 & $22 / 77=0,2857$ \\
\hline $\begin{array}{l}\text { Universitas Negeri } \\
\text { Gorontalo }\end{array}$ & 623 & 16.773 & 6260 & $0 / 53=0,1739$ \\
\hline $\begin{array}{l}\text { Universitas Pendidikan } \\
\text { Ganesha }\end{array}$ & 419 & 13.347 & 4030 & $1 / 42=0,3846$ \\
\hline
\end{tabular}

Perhitungan untuk mendapatkan tingkat efisiensi Universitas LPTK dilakukan dengan menggunakan bantuan software OSDEA yang mampu menghitung beberapa jenis metode DEA. Gambar 1 adalah tampilan awal dari perangkat lunak OSDEA yang dipergunakan. 


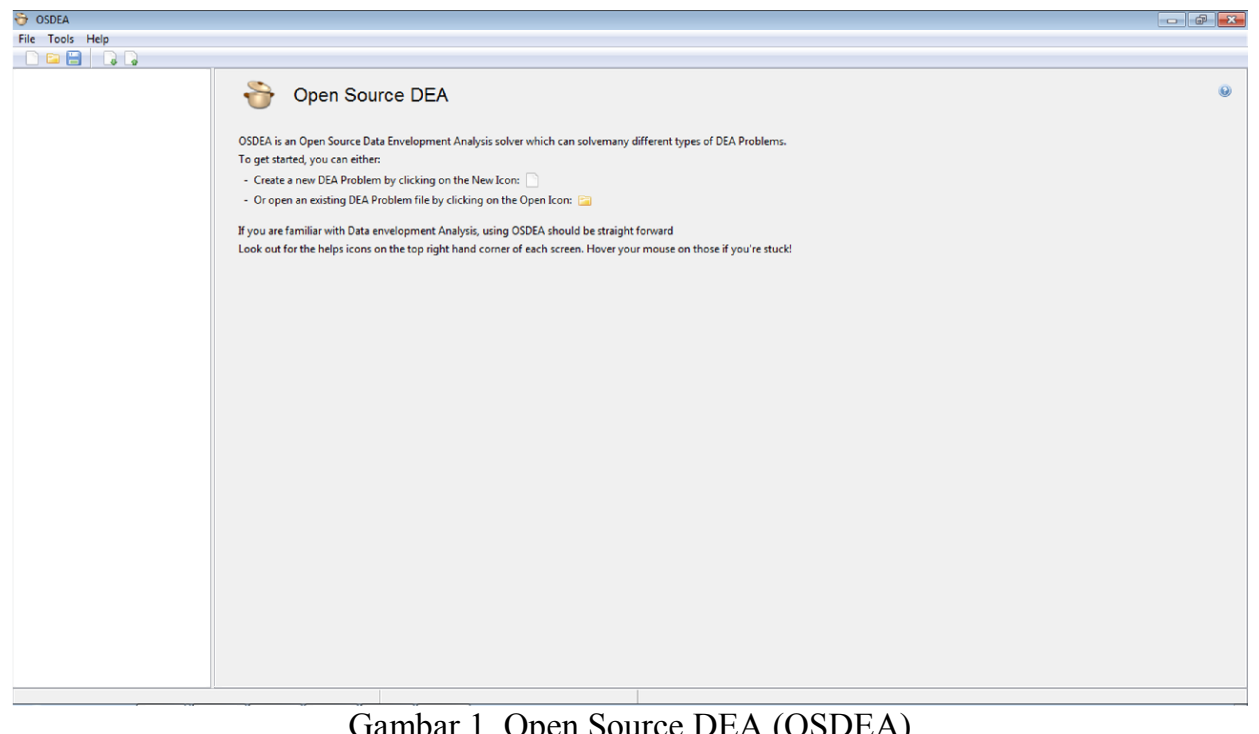

Keempat variabel yang menjadi dasar perhitungan di dalam software adalah jumlah staf pengajar tetap dan banyaknya mahasiswa s1,s2,s3 aktif di universitas sebagai input dan jumlah publikasi yang dihasilkan civitas akaemika di internet dan persentase dari prodi yang mendapatkan akreditasi A di universitas sebagai output. Dalam perhitungan efisiensi universitas LPTK ini dipergunakan metode CCR sebagai model utama. Gambar 2 menunjukkan proses perhitungan yang sedang dilakukan untuk data kedua belas universitas dengan metode DEA.

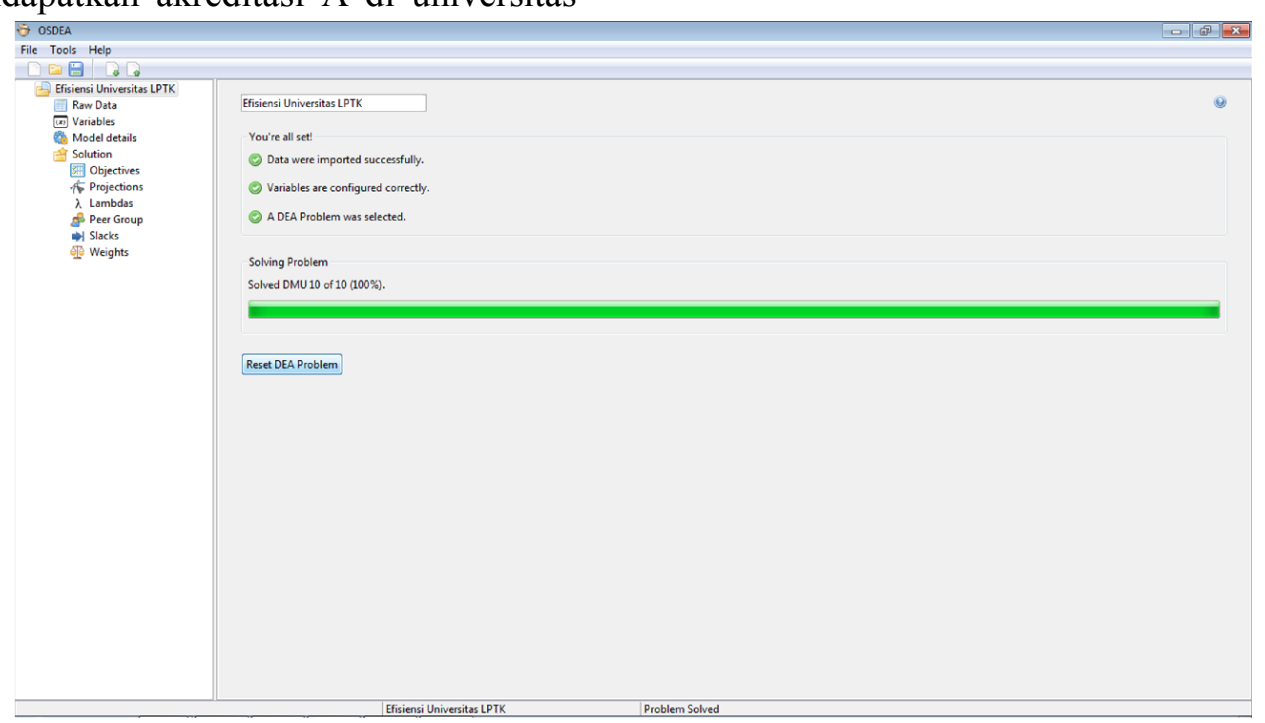

Gambar 2. Proses Perhitungan DEA dengan OSDEA

Semua universitas yang tidak memiliki efisiensi 1 harus berusaha untuk menjadi efisien dengan cara: mengurangi input sambil menjaga konstan output (ini merupakan pendekatan yang berorientasi input), meningkatkan output sekaligus mempertahankan input konstan (ini merupakan pendekatan yang berorientasi keluaran, atau model ketiga yaitu berusaha untuk mengurangi input sekaligus meningkatkan output. 
Tabel 2. Hasil Perhitungan Efisiensi Universitas LPTK

\begin{tabular}{|l|r|l|}
\hline DMU Name & Objective Value & Efisien \\
\hline Universitas & & \\
Negeri Padang & 0,410679875 & \\
\hline Universitas & & Ya \\
Negeri Malang & & \\
\hline $\begin{array}{l}\text { Universitas } \\
\text { Pendidikan } \\
\text { Indonesia }\end{array}$ & & Ya \\
\hline $\begin{array}{l}\text { Universitas } \\
\text { Negeri Manado }\end{array}$ & 0,047516329 & \\
\hline $\begin{array}{l}\text { Universitas } \\
\text { Negeri Makassar }\end{array}$ & 0,310661557 & \\
\hline $\begin{array}{l}\text { Universitas } \\
\text { Negeri Jakarta }\end{array}$ & 0,892492329 & \\
\hline Universitas & & \\
Negeri & & \\
Yogyakarta & 0,918591644 & \\
\hline $\begin{array}{l}\text { Universitas } \\
\text { Negeri Surabaya }\end{array}$ & 0,596574393 & \\
\hline $\begin{array}{l}\text { Universitas } \\
\text { Negeri Medan }\end{array}$ & 0,627301486 & \\
\hline $\begin{array}{l}\text { Universitas } \\
\text { Negeri Semarang }\end{array}$ & 0,706778217 & \\
\hline
\end{tabular}

Semua universitas yang tidak memiliki efisiensi 1 harus berusaha untuk menjadi efisien dengan cara: mengurangi input sambil menjaga konstan output (ini merupakan pendekatan yang berorientasi input), meningkatkan output sekaligus mempertahankan input konstan (ini merupakan pendekatan yang berorientasi keluaran, atau model ketiga yaitu berusaha untuk mengurangi input sekaligus meningkatkan output. Dari hasil perhitungan pada tabel 3 terlihat bahwa Universitas Negeri Malang dan Universitas Pendidikan Indonesia merupakan dua universitas dengan nilai efisiensi tertinggi di Indonesia. Berturut-turut diikuti oleh Universitas Negeri Yogyakarta, Universitas Negeri Jakarta, Universitas Negeri Semarang, dan Universitas Negeri Medan. Urutan keenam ditempati Universitas Negeri Surabaya dan ketujuh sampai keduabelas ditempati oleh Universitas LPTK di luar jawa, hal ini menunjukkan rata-rata efisiensi LPTK di Jawa masih lebih baik dibandingkan dengan rata-rata efisiensi LPTK luar Jawa.

\section{SIMPULAN}

Perhitungan efisiensi dari sebuah universitas sangat dipengaruhi oleh perbandingan dari output dan input. Semakin banyak ouput yang dihasilkan dengan menggunakan input yang sedikit akan meningkatkan efisiensi dari universitas. Perhitungan dari efisiensi menunjukkan bahwa efisiensi universitas LPTK di Jawa secara umum lebih baik dibandingkan dengan universitas LPTK di luar Jawa.

\section{DAFTAR PUSTAKA}

Abbott, M. \& Doucouliagos, C. (2003). The efficiency of Australian universities: a data envelopment analysis. Economics of Education review, Vol. 22, No. 1, pp. 89-97.

Afonso, A. \& Santos, M. (2005). Students and teachers: a DEA approach to the relative efficiency of Portuguese universities. NEP: New Economics Papers Education.

Ahn, T., Charnes, A. \& Cooper, W.W. (1988). Some statistical and DEA evaluations of relative efficiencies of public and private institutions of higher learning. Socio-Economic Planning Sciences, Vol. 22, No. 6, pp. 259-269.

Altbach, P.G. (2004). The costs and benefits of world-class universities. Academe, Vol. 90, No. 1, pp. 20-23.

Breu, T.M. \& Raab, R.L. (1994). Efficiency and perceived quality of 
the nation's â€œtop 25â€ National Universities and National Liberal Arts Colleges: An application of data envelopment analysis to higher education. Socio-Economic Planning Sciences, Vol. 28, No. 1, pp. 33-45.

Coelli, T., Prasada Rao, D. S., \& Battese, G. E. (1998). An introduction to efficiency and productivity analysis. Boston: Kluwer Academic.

Charnes, A.W., Cooper, W.W. \& Rhodes, E. (1978). Measuring Efficiency of Decision Making Units. European Journal of Operational Research, Vol. 2, pp. 429-444.

FÃ,rsund, F.R. \& Kalhagen, K.O. (1999). Efficiency and productivity of Norwegian colleges. Memorandum, Department of Economics, University of Oslo.

Flegg, A.T., Allen, D.O., Field, K. \& Thurlow, T.W. (2003). Measuring the efficiency and productivity of British Universities: an application of DEA and the Malmquist approach. University of the West of England, Department of Economics, series Discussion Papers, No. 304.

Joumady, O. \& Ris, C. (2005). Determining the relative efficiency of European Higher Education institutions using DEA. University of New Caledonia, ROA Maastricht University.

Rhodes, E.L. \& Southwick, L. (1986). Determinants of efficiency in public and private universities. Department of Economics, University of South Carolina.

Tone, K. (2001). A slacks-based measure of efficiency in data envelopment analysis. European journal of operational research, Vol. 130, No. 3, pp. 498-509. 